\title{
Human memory in narratives and stories: Implications for nursing research
}

\section{Introduction}

Stories enable us to explore hidden experiences (East et al 2010) or 'unknown unknowns' and are a way for people who have been through illness to share their experiences (Frank 2016). Much research is dependent on human memory (Barusch 2011) and qualitative research in particular relies on people telling stories or accounts to describe their experiences (Palacios et al 2015). Nursing research especially focuses on people's experiences of health and illness (Bonis 2008). Qualitative research can inform and facilitate positive change in health research (Streubert \& Carpenter 2011) and focuses on the "meaning rather than the measurement" (Holloway \& Biley 2011 p.968). One of the ways meaning can be explored is through asking people about their experiences. Participants are often invited to share their stories with researchers via interviews, focus groups or other means, and their memory is crucial to communicating these.

The nature of much nursing research can be described as sensitive (Dempsey et al 2016). Here again memory plays a role, participants are asked to draw on memories of experiences that may be distressing or that may raise unanticipated issues for them. These can have serious consequences and remembering these events can trigger thoughts and emotions which can lead to Post-Traumatic Stress Disorder (PTSD) (McNally 2010).

As a concept, memory is rarely discussed or described within qualitative nursing research. Rather, it is taken for granted and there is little acknowledgement that memory is much more complex than a simple storage and retrieval system. A discussion of the implications of this 
for qualitative nursing research is therefore timely. Furthermore, specific considerations on how to support participants recalling negative or traumatic events are pertinent.

\section{Aim}

The aim of this paper is to consider the implications of memory for qualitative nursing research. This will be achieved by exploring the following issues:

- What is memory and what are the implications for its use in research?

- Sensitive or traumatic memories: How can research participants be best supported in qualitative research?

\section{Literature Search}

Literature exploring human memory and the methodological implications of this for nursing research is not common. The literature for this paper was identified via a series of database searches in CINAHL and PsycholNFO, using the following keywords Memory, Methodology, Qualitative. These search terms were also used to search within specific top ranking nursing journals, as per their impact factor: Journal of Clinical Nursing, International Journal of Nursing Studies, Journal of Nursing Scholarship, Nurse Education Today, and Journal of Advanced Nursing. In addition, journals focusing on qualitative methods were also searched: Qualitative Health Research and Qualitative Research. Citation searches using Web of Science were used to further complement the search. Additionally a specialist healthcare librarian was consulted in order to check the searches and to suggest further reading.

The literature search was conducted to explore articles that discuss methodological implications of recall or memory in nursing research or how memory may impact on meaning 
creation in qualitative research. The majority of the articles focused on memory disorders, cognition or memory function. Thus, suggesting that as a concept, memory is rarely discussed or described. Rather, it is taken for granted and with little acknowledgement that memory is much more complex than a simple storage and retrieval system.

\section{Memory and nursing research}

Memory is described as being formed by the processes of acquisition, storage and retrieval (Gleitman et al 2007). It is complex with no agreed theory that explains what memory is and how it works (Baddeley et al 2015). Memory can include many different types which includes semantic (an individual's' store of knowledge about the world), episodic (memory of specific events) (Baddeley et al 2015) and autobiographical (memory for the events of one's own life) (Eysenck \& Keane 2015). Psychologists view memory as vitally important to humans and suggest that without memory there is no knowledge, no recollection, and no reflection (Gleitman et al 2007).

Autobiographical memory is of particular importance to nursing research as this form of memory is used to answer questions about past experiences. Autobiographical memory encompasses the memories about ourselves, personal interpretation and the environment around us (Baddeley et al 2015) and is deeply concerned with the self. Autobiographical memories can be influenced by social and emotional influences (Baddeley et al 2015). Memories are constructed in a context as opposed to being "called up like a book being chosen from a library" (Baddeley et al 2015 p.313). Thus, individual memory, as explored within qualitative interviews is both deemed to be socially constructed and co-constructed. Memories are essentially social and how they are recounted is to a certain extent determined 
by social context (Jedlowski 2001). Furthermore, the dialogue that takes place between researcher and narrator affects memories that are reported, as the way the relationship is structured and perceived can alter the memories (Jedlowski 2001). Jedlowski (2001) argues that "it is always possible for the past to present itself differently in a different discursive context (p.33)"; thus memories also depend on the questions being asked of participants in the present.

What and how people recall events is also connected to the meaning ascribed to those events. Furthermore, as noted above, autobiographical memory has a self-representation function (Baddeley et al 2015); hence, memory and meaning are linked. As Gaydos (2005) describes, meaning within personal narratives is partly created through the use of self-defined memories. These memories are created through combining and merging how an event is perceived with ensuing information, thoughts, events, feelings. Over time, memories then develop and become intertwined with the contexts we live in to create a self-story thereby forming part of the creation of meaning (Gaydos 2005).

Memories also exist within a "hierarchy of meaning" (Gaydos 2005 p.256), whereby what an individual remembers is significant to that person, and so is already imbued with meaning (Cohen et al 2010). Memory is also a vehicle that can be used by people to create identity by interpreting the past, however traumatic - in order to attribute a meaning of events that is acceptable to them. Creating meaning out of traumatic events is undertaken in this way and makes the past traumatic episode meaningful to the present self (Cohen et al 2010). Remembering why and how an individual has survived an experience and how they have been able to live meaningfully after it builds resilience (Cohen et al 2010). Thus, memory is integral 
to identity creation (Baddeley et al 2015), and is mirrored in healthcare contexts among individuals searching for meaning when experiencing illness (Skaggs \& Barron 2006).

Memory retrieval is imperfect (Baddeley et al 2015) and each time a memory is recalled it is modified (Rojahn 2013) leading to the potential for memories to be distorted or changed over time. The emotion or detail associated with a memory may not always reflect its accuracy (Laney \& Loftus 2013). Some people who have difficulty remembering even reconstruct their memories with experiences from the news, films or dreams (Baddeley et al 2015). Thus, memory is malleable and can be affected by something as simple as a leading question (Laney \& Loftus 2013). Lacy and Stark (2013) describe how people have been wrongly convicted for crimes they did not commit on the basis of eye witnesses' recollections of events. The judicial system is acutely aware of this and "false memories" are discussed when considering eye witness accounts in court (Howe \& Knott 2015).

Memories are also conceptualised as tools people use to make sense of their past and can influence how they view their present and future - they effectively help create people's identities, enabling individuals to make sense of events and their experiences of them (Keightley 2010). What and how an individual remembers can be affected by cultural, social, and wider contexts (Wilkinson 1997; Keightley 2010; Bietti et al 2014; Winter 2016), which means there is the potential for individuals to remember only elements of an event (Wilkinson 1997). Cultural and family norms can also affect what and how things are remembered (Keightley 2010) as can emotional state (Bietti et al 2014,) both at the time of the event and at the time the event is recalled. 
Therefore, one of the provisos when deciding to undertake qualitative nursing research should be an appreciation for the complexities of memory. Qualitative nursing research based on stories and narratives can highlight rich, complex memories that are imbued with meaning, and intertwined with issues of identity and context. Unpicking this and exploring meaning should form an important aspect of the analysis of these stories and narratives. The aim of this kind of research however, should not be to present a series of recalled events as if they were unchanged snapshots from the past.

\section{Sensitive or traumatic memories}

Memory, as a tool that enables people to make sense of their experiences (Keightley 2010) is particularly powerful when considering potentially traumatic events. These events can have serious consequences and discussing them can lead to grief, anxiety and distress (Elmir et al. 2011). Remembering these events can even trigger thoughts and emotions which can lead to Post-Traumatic Stress Disorder (PTSD) (McNally 2010; Baddeley et al 2015). Nurses are in an ideal position to assist people to make meaning out of challenging life events (Skaggs \& Barron 2006). However, as in clinical practice, nurses undertaking research should be mindful of the potential distress that traumatic memories can elicit and of their duty of care to members of the public (NMC 2015). In particular, ethical issues should be considered throughout the research process (Cutliffe \& Ramcharan 2002). Issues of privacy and confidentiality must be addressed and preventing or reducing the risk of psychological harm is an ethical requirement (Mealer \& Jones 2014). Despite the potential sensitivity of research there is a responsibility to conduct ethical research into the full range of patient experiences (Dempsey et al 2016). Furthermore, not conducting the research could be viewed as disempowering the public (Dempsey et al 2016). Ensuring the safety and comfort of both researcher and participant will 
ensure the full and complex extent of potentially sensitive memories can be explored in an ethically sound manner. This enables the rich meaning surrounding the memories to be captured and used when building a nursing evidence base.

In order to support participants possible strategies to help mitigate the impact of sensitive or traumatic memories should be considered. From the start when interviewing participants it is important to acknowledge power relations and remember participants are being invited to talk about their potentially sensitive memories, they are not being interrogated. Participants must remain in control at all times and their importance in research is paramount and should be acknowledged, without them there is no research (Halcomb \& Peters 2016). The interview setting should be considered, it is crucial this environment is suitable for the participant, and both the location and timing of the interview should be acceptable and appropriate for them (Doody \& Noonan 2013; Dempsey et al 2016). A safe space should be created; ideally this should be a place of the participant's choosing and somewhere that is comfortable, free from distractions and where they can speak confidentially (Doody \& Noonan 2013; Dempsey et al. 2016). The language during the interview should remain appropriate and acceptable to the participant (Karnieli-Miller et al 2009). It can be helpful to know your interview schedule well to enable the interview to flow in a conversational manner (Dempsey et al 2016). Active listening skills are key here as is the ability to develop rapport (Doody \& Noonan 2013) and attend gently to the participant's needs. When exploring issues with participants it is crucial to avoid leading questions especially as they could potentially impact on the creation of false memories (Laney \& Loftus 2013). To ensure participants are comfortable during the interview it is advised to make it clear to participants that they can take a break or stop at any time (Karnieli-Miller et al 2009). If at any point a participant were to become distressed following 
a distress protocol (Dempsey et al 2016) in line with ethical principles and local procedures is advised. The creation of this type of protocol is commonly a requirement of ethics committees and should be considered at the start of a project.

As the interview is drawing to a close it can be useful to clarify with the participant whether they have been able to say everything they would like to say before ending the interview, inviting them to add anything they feel has not been covered should they wish to. It is also at this moment that support to participants can be provided by clearly signposting to relevant local and national support services (Dempsey et al 2016). The importance of considering the potential for distress for the participant has been acknowledged however, there can also be positive aspects to discussing difficult memories. Being able to talk about these memories in a safe and supportive environment can help to build resilience (East et al 2010) and meaning can be obtained from these negative events. People also note that telling their stories as part of a research process can have positive outcomes as it can feel therapeutic or cathartic and promote healing (Elmir et al 2011; East et al 2010).

Researchers themselves are not immune to the effects of the memories recalled by participants and there is the risk of experiencing vicarious traumatisation during interviews and transcription (Elmir et al 2011). To ensure that researchers feel safe and supported during the research process it is important to acknowledge the fact that research is emotion work and it can be helpful to expect there to be emotional issues to deal with (Petty 2017). There is a need to create a clear plan to help deal with this whilst also acknowledging that there may be unanticipated issues that arise (Visser 2017). Ideally, this plan should consider the entire research process and contain a variety of strategies: It can be useful to identify sources of 
support at the start of the project and to incorporate time within the project plan to discuss and debrief whilst maintaining confidentiality (Petty 2017; Visser 2017). Researchers can seek out social networks and they can be used as a vital source of support for researchers (Petty 2017; Visser 2017) as can advice and supervision from more experienced researchers (Hockey 2007). Allowing time between interviews to pause, reflect and debrief can be beneficial to the researcher on an emotional level (Elmir et al 2011). Debrief is a helpful tool that can heighten self-awareness enabling researchers to seek out support where necessary and lower feelings of isolation (Ritchie et al. 2014). Furthermore, the debriefing process can normalise the challenges associated with qualitative research and aide active coping (Ritchie et al. 2014).

Emotional intelligence skills are particularly relevant in qualitative research and they can be used to deal with both the interview process and the data generated (Petty 2017). Reflexivity is a key element to this (Hockey 2007) and it is beneficial to have an understanding of any preconceptions that may be held (Halcomb \& Peters 2016). The position of the researcher should be considered, namely whether a professional background or previous role may have an impact on how relationships are built with participants (Halcomb \& Peters 2016). This can illustrate and strengthen rigour and ensure participant voices are at the forefront (Halcomb \& Peters 2016). Keeping a reflective journal can help a researcher with their reflexivity and can be a place for them to record and explore their thoughts, ideas and emotions (Petty 2017; Visser 2017) and can even be a protective tool for the researcher's wellbeing (Mealer \& Jones 2014). Researchers can use their journal to critically self-reflect, consider their values and preconceived ideas, and make the process of data analysis visible, thereby increasing transparency in the research process (Ortlipp 2008). Importantly, incorporating the contents of the reflective journal into the research can ensure emotions are not kept on the sidelines 
(Visser 2017). Furthermore, taking notes and reflecting post interview is useful and may assist to uncover the "emotional truths" (defined as the ways a memory is expressed) (Jedlowski 2001) being communicated by participants.

\section{Implications for qualitative research}

This discussion concerning memory highlights that memories are complex and subjective and should not be taken for granted in research. It is precisely this richness that renders them powerful; the meanings underpinning them are central to qualitative inquiry (Holloway \& Biley 2011). In clinical nursing practice, a subjective description of pain is not dismissed rather it is taken seriously and acted upon (RCN 2015) similarly to how memories within stories and narratives can be conceptualised. Thus, within qualitative research it is acceptable to value experiences and feelings over any alleged accuracy. This is congruent with knowing in nursing which focuses on individual experiences of health and illness (Bonis 2008).

An understanding that certain memories may be sensitive or traumatic was deemed an important point of discussion. Stemming from this strategies to help support both researchers and participants were outlined. Though these strategies are not new to qualitative researchers they take on a new importance when viewed in relation to memory. As noted, memories are complex and context dependent thus these strategies also attempt to create the optimum environment for participants to be able to discuss their memories.

\section{Conclusion}


The concept of memory has been defined and discussed in relation to qualitative nursing research. Memories are not photographic recollections of past events, rather they are complex, context dependent and imbued with meaning and; they are ideally suited to qualitative inquiry. Due to the potentially sensitive or traumatic nature of memories care should be taken. Relevant strategies to support both participants and researchers were highlighted.

References 
Baddeley A, Eysenck MW, Anderson MC (2015) Memory. Second edition. Psychology Press, London.

Barusch AS (2011) New understanding of memory poses challenges for retrospective research. Journal of Gerontological Social Work. 54, 8, 751-754.

Bietti LM, Stone CB, Hirst W (2014) Contextualising human memory. Memory Studies. 7, 3, 267-271.

Bonis SA (2009) Knowing in nursing: a concept analysis. Journal of Advanced Nursing. 65, 6, $1328-1341$.

Cohen HL, Meek K and Lieberman M (2010) Memory and Resilience. Journal of Human Behaviour in the Social Environment. 20, 4, 525-541.

Cohen-Cruz J and Schutzman M (2005) A Boal companion: dialogues in theatre and cultural politics. London: Routledge.

Cutcliffe JR and Ramcharan P (2002) Leveling the Playing Field? Exploring the Merits of the Ethics-as-Process Approach for Judging Qualitative Research Proposals. Qualitative Health Research 12, 7, 1000-1010.

Dempsey L, Dowling M, Larkin P et al. (2016) Sensitive interviewing in qualitative research. Research in Nursing \& Health. 39, 6, 480-490. 
Doody O and Noonan M (2013) Preparing and conducting interviews to collect data. Nurse Researcher. 20, 5, 28-32.

East L, Jackson D, O'Brien L et al. (2010) Storytelling: an approach that can help to develop resilience. Nurse Researcher. 17, 3, 17-25.

Eysenck MW and Keane MT (2015) Cognitive Psychology: A student's handbook. Seventh edition. Taylor and Francis Group: London.

Frank A W (2016) From sick role to narrative subject: an analytic memoir. Health. 20, 1, 9-21.

Gaydos HL (2005) Understanding personal narratives: an approach to practice. Journal of Advanced Nursing. 49, 3, 254-259.

Gleitman H, Reisberg D and Gross J (2007) Psychology. Seventh edition. W.W. Norton \& Company: London.

Halcomb E and Peters K (2016) Research would not be possible without participants. Nurse Researcher. 24, 1, 6-7.

Hockey J (2007) Closing in on death? Reflections on research and researchers in the field of death and dying. Health Sociology Review. 16, 5, 436-446. 
Holloway I and Biley F C (2011) Being a qualitative Researcher. Qualitative Health Research. $21,7,968-975$.

Howe ML and Knott LM (2015) The fallibility of memory in judicial processes: Lessons from the past and their modern consequences. Memory. 23, 5, 633-656.

Jedlowski P (2001) Memory and sociology - themes and issues. Time and Society. 10, 1, 2944.

Karnieli-Miller O, Strier R and Pessach L (2009) Power relations in qualitative research. Qualitative Health Research. 19, 2, 279-289.

Keightley E (2010) Remembering research: memory and methodology in the social sciences. International Journal of Social Science Methodology. 13, 1, 55-70.

Lacy JW and Stark CEL (2013) The Neuroscience of Memory: Implications for the Courtroom. Nature Reviews Neuroscience. 14, 9, 649-658 doi:10.1038/nrn3563.

McNally RJ (2010) Can we salvage the concept of psychological trauma? The Psychologist. 23, 386-389.

Mealer M \& Jones J (2014) Methodological and ethical issues related to qualitative telephone interviews on sensitive topics. Nurse Researcher. 21, 4, 32-37. 
Misztal B A (2003) Theories of social remembering. Open University Press, Maidenhead.

Nursing and Midwifery Council (NMC) (2015) The Code. Available at: https://www.nmc.org.uk/globalassets/sitedocuments/nmc-publications/nmc-code.pdf (Accessed 06/02/2018).

Ortlipp M (2008) Keeping and using reflective journals in the qualitative research process The Qualitative Report 13, 4, 695-705.

Palacios JF, Benissa S, Hodge FS et al (2015) Storytelling: A qualitative tool to promote health among vulnerable populations. Journal of Transcultural Nursing. 26, 4, 346-353.

Petty J (2017) Emotion work in qualitative research: interviewing parents about neonatal care. Nurse Researcher. 25, 3, 26-30.

Ritchie J, Lewis J, McNaughton Nicholls C et al. (2014) Qualitative research in practice. Second edition. SAGE: London.

Rojahn S Y (2013) Memory Is Inherently Fallible, And That's a Good Thing Available at: https://www.technologyreview.com/s/520156/memory-is-inherently-fallible-and-thats-agood-thing/ (Accessed 06/02/2018). 
Royal College of Nursing (RCN) (2015) RCN Pain Knowledge and Skills Framework for the Nursing Team. Available at: https://www.rcn.org.uk/library/subject-guides/pain (Accessed 19/08/2018).

Schiller D, Monfils MH, Raio CM et al. (2010) Preventing the return of fear in humans using reconsolidation update mechanisms. Nature. 463, 49-53. doi:10.1038/nature08637.

Skaggs BG and Barron CR (2006) Searching for meaning in negative events: concept analysis. Journal of Advanced Nursing. 53, 5, 559-570.

Streubert HJ and Carpenter DR (2011) Qualitative research in nursing: Advancing the humanistic imperative. Fifth edition. Lippincott Williams \& Wilkins, Sydney, New South Wales.

Visser RC (2017) "Doing death": Reflecting on the researcher's subjectivity and emotions. Death Studies. 41, 1, 6-13.

Wilkinson J (1997) Understanding memory to enhance nursing practice. British Journal of Nursing. $6,13,741-744$.

Winter G (2016) The fragility of memory. British Journal of Neuroscience Nursing. 12, 4, 197. 